\title{
Domino-type progressive collapse analysis of a multi-span simply-supported bridge: a case study
}

\author{
Kaiming $\mathrm{Bi}^{\mathrm{a}}$, Wei-Xin Ren ${ }^{\mathrm{b},}$, Pi-Fu Cheng ${ }^{\mathrm{c}}$, Hong Hao ${ }^{\mathrm{a}}$ \\ ${ }^{a}$ Department of Civil Engineering, Curtin University, Kent Street, Bentley WA 6102 \\ ${ }^{b}$ School of Civil Engineering, Hefei University of Technology, Hefei 230009, China \\ ${ }^{c}$ Changsha Planning \& Design Institute CO., LTD, Changsha 410007, China
}

\begin{abstract}
Hongqi Viaduct, a multi-span simply-supported bridge in Zhuzhou city, Hunan Province, China, collapsed progressively during the mechanical demolishing of the bridge on May 17, 2009. Totally nine spans collapsed in the accident and it is a typical Domino-type progressive collapse. The accident resulted in the loss of 9 lives and 16 injuries. Investigations were conducted after the accident to determine the cause of the unexpected progressive collapse. This paper is aimed at presenting a summary of the bridge before and after the incident, the demolishing plans and field investigations after the accident. To better understand the cause and mechanism of the progressive collapse, a numerical simulation is carried out. A detail 3D finite element (FE) model is developed by using the explicit FE code LS-DYNA. The bridge components including the bridge slabs, wall-type piers, longitudinal and transverse reinforcement bars are included in the model. The nonlinear material behaviour including the strain rate effects of the concrete and steel rebar are considered. The model is used to simulate the bridge collapse induced by demolishing, and the domino-type progressive collapse of the bridge is clearly captured. Based on the numerical results, the reason for the failure is discussed and better understood. Finally, the possible mitigation methods of such progressive collapses of multi-span viaducts are suggested.
\end{abstract}

Keywords: Viaduct; domino-type progressive collapse; numerical simulation; failure analysis; mitigation method

*Corresponding author. Tel.: +86-551-62901432; fax: +86-551-62901432

Email address: renwx@hfut.edu.cn (W.X. Ren) 


\section{Introduction}

The spread of an initial local failure from element to element, eventually resulting in the collapse of an entire structure or a disproportionately large part of it has been known as “progressive collapse” [1]. Progressive collapse takes place when the loading pattern or boundary conditions of the structure changed such that structural elements are loaded beyond their ultimate capacity and fail. When any element fails, the remaining elements of the structure seek alternative load paths to redistribute the load applied to it. As a result, other elements may fail as well [2]. Progressive collapse is characterized by a distinct disproportion between the triggering event and the resulting widespread collapse [3]. These initial triggering events may include, for example, gas explosion, blast, foundation failure, vehicle or ship/barge impact, fire, earthquake and wind loads.

Many bridge progressive collapse incidents have been reported in the history. These incidents include for example, the Tacoma Narrows Bridge (a suspension bridge in Washington State, USA) failed dramatically during a wind storm after only four months of service in 1940, and failure of the plate girders used to stiffen this bridge was the suspected source triggering the collapse [4]. The Silver Bridge (an eyebar suspension bridge in Ohio, USA) collapsed without warning on December 15, 1967 after 40 years of service due to the failure of a defective eyebar [4]. The Viadotto Cannavino Bridge (a four-span continuous girder bridge in Italy) partially collapsed during construction in 1972, and the triggering event was a formwork failure [3]. The Haeng-Ju Grand Bridge (a continuous prestressed concrete girder bridge in Seoul, Korea) collapsed progressively during construction in 1992, and the forces transmitted by the continuous prestressing tendons enabled the collapse to progress [3]. The Tuojiang Bridge (a 4-span stone arch bridge in Fenghuang, China) collapsed unexpectedly in 2007 when the temporary supports near the primary arch of the first span were removed [5]. The I-35W Mississippi River Bridge (a steel deck truss 
bridge in Minneapolis, USA) collapsed in 2007 due to the loss of one single gusset plate on the bottom chord connection [6]. More recently the Hongqi Viaduct (a multi-span simplysupported bridge in Zhuzhou city, Hunan Province, China), the subject of this paper, collapsed during the mechanical demolishing of a simply-supported span, but triggered the progressive collapse of nine adjacent spans of the bridge on May 17, 2009. All these catastrophic incidents result in not only enormous economic losses but also human lives.

For different structures, the progressive collapse mechanisms may be different. Starossek divided them into 6 different types [7], i.e., pancake-type collapse, zipper-type collapse, domino-type collapse, section-type collapse, instability-type collapse and mixtype collapse. These 6 different types were further classified into 4 categories: both zippertype and section-type collapses are most strongly characterized by the redistribution of forces carried by failing elements in the remaining structures, and they are termed as redistribution class. In pancake-type collapse and domino-type collapse, a substantial amount of potential energy is transformed into kinematic energy during the fall and overturing of elements and subsequently reintroduced into the structure, and they are named as impact class. The instability-type collapse and mix-type collapse form one class on its own respectively. More detailed information about different types and classes of progressive collapse can be found in [7]. For the bridge progressive collapse incidents mentioned above, the collapse of Tacoma Narrows Bridge is a typical zipper-type collapse [3], while the collapse of Haeng-Ju Bridge is a mix-type collapse involved in zipper-type and domino-type categories [3]. It will be demonstrated that the collapse of Hongqi Viaduct is a typical domino-type collapse.

Progressive collapse is a nonlinear dynamic process, which makes the quantitative analyses of progressive collapse quite complicated. Moreover, a detailed numerical model is usually required to realistically capture the collapse process of the structure, which 
makes solving the problem very time consuming and more daunting. With the rapid development of computational facilities, some quantitative investigations of collapse have begun to be reported recently especially after the collapse of the World Trade Centre on September 11, 2001. These studies mainly focus on the buildings [8-12] or frame structures [13-15]. Researches on the bridges are, however, relatively scarce. Ghali and Tadros [16] carried out dynamic analyses and experimental verification on the Confederation Bridge, and concluded that inappropriate choice of the static system can produce a structure vulnerable to progressive collapse. By taking the same bridge as an example, Starossek [17] discussed the analysis strategy and the ensuing impact on the design of this bridge. Wolff and Starossek [18] examined the structural responses of a cable-stayed bridge to the loss of any one cable based on a 3D model. The effects of cable sag, transverse cable vibrations and structural damping were evaluated and the dynamic amplification factor was computed and the code recommendations were discussed. The robustness of the bridge was then further assessed [19]. Hao and Tang [20] investigated the blast loading effects on a large cable-stayed bridge. The progressive collapse analyses of the bridge structure after damage occurring in either one of the four main bridge components were performed. Aoki et al. [21] carried out static and dynamic analyses of a cable-stayed bridge designed to Australian standards. The dynamic amplification and demand-to-capacity ratio in different structural components including cables, towers and the deck were calculated. The effects of location, duration and number of cable(s) loss as well as effect of damping level on the progressive collapse resistance of the bridge were studied and importance of each factor on the potential progressive collapse response of the bridge was investigated. Xu et al. [5] numerically simulated the progressive collapse of a typical multi-span stone arch bridge. The collapse process was replicated and the importance indices of all structural elements were evaluated. 
It is obvious that previous studies on bridge progressive collapse are relatively sporadic, and most of them [16-21] examined the progressive collapse potential only, but not on a systematic simulation of the entire collapse process. Moreover, a reliable analytical model and methodology is important for design of bridge structures against progressive collapse. Such analytical models are, however, relatively limited. This paper presents a case study on a typical multi-span simply-supported bridge, which collapsed progressively during the mechanical demolishing of the bridge. A detailed 3D finite element model, including the bridge slabs, wall-type piers, longitudinal and transverse reinforcement bars, is developed based on ANSYS [22]. The non-linear material behaviour including the strain rate effects of the concrete and steel rebar are considered. The nonlinear dynamic analyses are carried out by using the explicit finite element code LS-DYNA [23]. The domino-type progressive collapse process is replicated and the reason for failure is examined.

\section{Hongqi Viaduct}

\subsection{Bridge description}

Hongqi Viaduct is a multi-span simply-supported bridge located in Zhuzhou city, Hunan Province, China. It includes 121 piers and 122 spans, with 15 spans of length $13 \mathrm{~m}, 3$ spans of $18 \mathrm{~m}$ and 104 spans of $20 \mathrm{~m}$. The total length of the bridge reaches $2329 \mathrm{~m}$. Fig. 1 shows the bridge before collapse. Each span consists of 16 prestressed concrete hollow slabs. The height of each slab is $0.85 \mathrm{~m}$ and the width is $1 \mathrm{~m}$. The total width of the superstructure is $16.5 \mathrm{~m}$ including $0.25 \mathrm{~m}$ overhang in the first and last hollow slab as shown in Fig. 2, with an equivalent density of $2241 \mathrm{~kg} / \mathrm{m}^{3}$. The height of the wall-type pier is $7.875 \mathrm{~m}$ from the pile cap and the thickness is $0.8 \mathrm{~m}$. Fig. 2 shows the numbering of the slabs and the cross sections of the pier. The superstructures are simply-supported by 7808 laminated rubber bearings located on the top of the piers. 
Fig. 3 illustrates the reinforcement bars in the piers. Deformed steel bars with diameter of $1.8 \mathrm{~cm}(\phi 18)$ were pre-buried in the pile cap. The length of these pre-buried bars is 267.5 $\mathrm{cm}$ with $60 \mathrm{~cm}$ buried in the pile cap and the spacing is $8 \mathrm{~cm}$. The size of the rest vertical bars is $1.2 \mathrm{~cm}(\phi 12)$, and the spacing varies with the height of the pier, with $8 \mathrm{~cm}$ between sections $\mathrm{A}-\mathrm{A}$ and $\mathrm{B}-\mathrm{B}, 16 \mathrm{~cm}$ between sections $\mathrm{B}-\mathrm{B}$ and $\mathrm{C}-\mathrm{C}$ and $24 \mathrm{~cm}$ between section $\mathrm{C}-\mathrm{C}$ and the top of the pier. The transverse stirrups are round steel bars. The diameter is 1.0 $\mathrm{cm}(\phi 10)$, and the spacing between the transverse bars is $25 \mathrm{~cm}$.

\subsection{Demolishing scheme and progressive collapse}

Two different methods were adopted to demolish Hongqi Viaduct, i.e. blasting demolishing method and mechanical demolishing method. The spans between piers \#12 and \#100 were demolished by using the blasting method and the rest spans were planned to be demolished by mechanical method. The original scheme of mechanical method was to remove the connections between any two hollow slabs first, and then a hydraulic breaker located on the adjacent span would be used to break the first hollow slab. The broken hollow slab would drop to the ground due to the gravity load. Then the hydraulic breaker would move to break the second slab. This process would be repeated until the total 16 slabs being demolished successively. The breaking location of the slab by the breaker is about $1.4 \mathrm{~m}$ to the left end of the slab. Fig. 4 shows the mechanical demolishing method.

Unfortunately the actual demolishing process did not exactly follow the original plan. On May 17, 2009, when demolishing the slabs between piers \#110 and \#109, to speed up the process, the last 4 slabs, i.e. slabs $13-16$ in Fig. 2, were demolished together first, and then the hydraulic breaker was moved to break the remaining 12 slabs, which resulted in the 12 slabs dropping to the ground simultaneously. The left ends of these 12 slabs dropped to the ground but their right ends collided with pier \#109, generating a huge impacting force on the pier. The huge impacting force from the collapsing slabs on the pier, which 
was not designed to resist such an impacting force, seriously damaged pier \#109 and made it collapse toward pier \#108. Consequently, the left ends of the slabs between piers \#109 and \#108 dropped to the ground due to the loss of support (pier \#109), and the right ends collide with pier \#108, which in turn resulted in the collapse of pier \#108. The adjacent spans followed the same pattern and formed the domino-type progressive collapse as illustrated in Fig. 11. However, the collapse did not progress to the whole remaining bridge spans but stopped at pier \#101, which deformed toward pier \#100 with an angle of 30 degrees due to impact by the collapsed span but did not collapse as shown in Fig. 6(d). The collapsed spans and piers are designed and constructed the same. The reason why pier \#101 did not completely collapse as piers \#109 to \#102 is not exactly known. Because the post incident investigation concentrated on the collapsed spans, no further information is available on pier \#101. In this study, only the collapse mechanism is investigated. Totally 8 piers and 9 spans collapsed in the incident, and the collapsed length reached 180 m. Fig. 5 shows the plan view of the collapsed spans and Fig. 6 shows the bridge after collapse. 9 people died and 16 were injured in the incident.

\subsection{Site investigation}

An investigation team was organized immediately after the incident. One important task of the team was to collect the concrete and reinforcement samples from the slabs and the piers. These samples were tested at the structural lab in Central South University in Changsha, China. For the slabs, 6 samples with diameter of $10 \mathrm{~cm}(\phi 100)$ were drilled from the slabs between piers \#110 and \#109, and between piers \#108 and \#107. The pier samples were drilled from piers \#106, \#108 and \#109, and 3 \$100 samples were drilled from each pier. $43 \phi 12$ reinforcement samples, $9 \phi 18$ samples and $12 \phi 10$ samples were also collected from these piers. Fig. 7 shows part of the collected concrete and reinforcement samples. The test results found that the average compressive strengths of concrete of the slab and 
pier are 64.1 MPa and 38.7 $\mathrm{MPa}$, respectively. The average yield strength and ultimate strength of the reinforcement bars are shown in Table 1 . These tested data are used in the numerical model of the bridge in this study.

\section{Numerical Simulation}

To better understand the cause of the above progressive collapse incident, the mechanism of RC slabs impact on bridge pier, pier damage and collapse under slab impacting force are simulated in this section through numerical investigations.

\subsection{Elements}

A detailed 3D finite element (FE) model of the bridge is developed in the software package ANSYS [22], and the analyses are carried out by using the explicit finite element code LSDYNA [23]. Fig. 8 shows the elevation view of the FE model. To model the structural damage under impact loads and collapse, fine element mesh is needed, which usually results in huge FE models. To reduce the computational effort, without losing generality, only two spans and three piers (piers \#110 to \#108) are considered in the model. For the three piers, detailed modelling is only applied to pier \#109, the pier that collapsed owing to the impact by the free falling span. In the detailed model the concrete and reinforcement bars are modelled separately, with constant stress solid elements for concrete and Belytschko beam elements for reinforcement bars. By conducting a numerical convergence test on various mesh sizes $(0.16,0.08$ and $0.04 \mathrm{~m})$, it was found that the $0.08 \mathrm{~m}$ mesh yields similar results with the smaller mesh but with much less computational time. A mesh size of $0.08 \mathrm{~m}$ is therefore used to model pier \#109 for both solid concrete elements and beam elements for reinforcement bars.

Perfect bond is assumed in the study to model the connections between the reinforcement and concrete. Hence, the bond slip between the reinforcements and concrete is taken as a 
property fully dependent on failure of concrete material. For piers \#110 and \#108, smeared model (i.e. reinforcement assumed to be uniformly distributed over concrete element) with element size of about $0.25 \mathrm{~m}$ is used to minimize the computational effort. Fine mesh is also applied to the span segments with possible contacts during impacts with ground and piers, (i.e., parts (1)-(4)), e.g., part (1) will contact with ground after the demolishing part (5) is removed and the falling span hits the ground; whereas part (2) will impact pier \#109. Relatively coarse meshes are applied to the other parts of the slabs. Smeared model is also adopted for the slabs. The length of each zone is shown in Fig. 8.

\subsection{Contacts and boundary conditions}

The penalty method is adopted to model the contact interfaces between meshes because of its effectiveness and simplicity for explicit analysis. With this method slave nodes penetration is restricted via the imaginary normal interface springs between the shooting nodes and the contact surfaces [23]. The contact algorithm of *CONTACT AUTOMATIC SURFACE TO SURFACE in LS-DYNA is employed to avoid penetrations at the interfaces between bridge girders and the supporting piers. Slabs will drop to the ground after the demolishing part being removed, part (1) will contact with ground, and part (2) will collide with pier \#109 and then slide to the ground along the surface of the pier. *CONTACT AUTOMATIC SURFACE TO SURFACE is adopted again to simulate these contacts. After part (2) colliding with pier \#109, the cover concrete of pier \#109 may suffer significant crushing damage due to the large impacting force and may be eroded to avoid computation overflow, and then part (2) may be in contact with the reinforcement bars in the pier, in this case the contact type of *CONTACT AUTOMATIC NODES TO SURFACE is defined to model RC slab and reinforcement bar contact. Similarly, these two contact algorithms are defined to model the contacts between part (3) and pier \#109. Since smeared model is adopted to simulate pier \#108, only the *CONTACT 
AUTOMATIC SURFACE TO SURFACE is applied during the colliding and sliding process between part (4) and pier \#108.

The ground is modelled by keyword *RIGIDWALL, which provides a simple way of treating contact between a rigid surface (ground) and the nodal points of deformed bodies [23]. The bases of the piers are fixed in the simulation.

\subsection{Material model}

\section{Both *MAT CONCRETE DAMAGE REL3 (MAT_72REL3) AND *MAT ELASTIC}

(MAT_1) material models are utilised to model the concrete in the present study. MAT_REL3 model is employed at pier \#109 where the damage of the pier will be modelled, while MAT_1 is used to model the smeared materials, i.e. piers \#110 and \#108 and slabs. The advantage of MAT_REL3 is that it can model the complex behaviour of concrete by specifying the unconfined compressive strength only, which has already been obtained from the laboratory test. Moreover, this material model also allows users to consider the strain rate effect which will be discussed in Section 3.4.

In order to avoid computer overflow during calculation, the card *MAT ADD EROSION is used to eliminate elements that have been damaged and do not further contribute to load resistance. In the present study, the concrete in pier \#109 will be deleted when the maximum principal strain reaches 0.3 or the tensile stress reaches $3.2 \mathrm{MPa}$. These two values are obtained based on a few trial-and-error tests. Because eroding away elements in numerical simulations violates conservation of mass and energy it should be used with caution. In continuum modelling and numerical simulations, erosion technique often has to be used to remove elements experienced excessive deformations and no longer contributing to the structural load-carrying capacities. Usually relatively large erosion criteria are used to avoid premature removal of structural elements. The erosion algorithm is also applied to remove the demolished part of the slab by the hydraulic breaker, i.e., part 
(5) shown in Figure 8. In this study, the hydraulic breaker is not modelled. The demolished part is simply removed from the model at $0.1 \mathrm{sec}$ to induce the free fall of the remaining deck.

The elastic-plastic material model *MAT PIECEWISE LINEAR PLASTICITY (MAT_24) is employed to model the steel reinforcements in pier \#109. The advantage of this model is that it allows users to define arbitrary stress-strain curves and it is a cost effective model to consider isotropic and kinematic hardening plasticity including strain rate effect. Table 2 lists all the material properties adopted in this study.

\subsection{Strain rate effect}

The strengths of the structural materials are strain rate dependent as their dynamic properties can be enhanced significantly when subjected to high speed impact such as blast [11, 20], barge impact [24] or earthquake loading [25]. Current study employs the dynamic increase factor $(D I F)$, a ratio of the dynamic to static strength against strain rate to account for the material strength enhancement with strain rate effect.

The bilinear relationship developed by CEB code [26] and Malvar and Ross [27] are applied in this study for the concrete strength enhancement. In tension, the DIF of the tensile strength is given by the following equations [27]:

$$
\begin{aligned}
& \text { TDIF }=\frac{f_{t}}{f_{t s}}=\left(\frac{\dot{\varepsilon}}{\dot{\varepsilon}_{t s}}\right)^{\delta} \text { for } \dot{\varepsilon} \leq 1 \mathrm{~s}^{-1} \\
& \text { TDIF }=\frac{f_{t}}{f_{t s}}=\beta\left(\frac{\dot{\varepsilon}}{\dot{\varepsilon}_{t s}}\right)^{1 / 3} \text { for } \dot{\varepsilon}>1 \mathrm{~s}^{-1}
\end{aligned}
$$

where $f_{t}$ is the dynamic tensile strength at strain rate $\dot{\varepsilon}$ in the range of $10^{-6}-160 \mathrm{~s}^{-1}, f_{t s}$ is the static tensile strength at $\dot{\varepsilon}_{t s}, \log \beta=6 \delta-2, \delta=1 /\left(1+8 f_{c}^{\prime} / f_{c o}^{\prime}\right), f_{c}^{\prime}$ is the static uniaxial compressive strength of concrete (in $\mathrm{MPa}$ ) and $f_{c o}^{\prime}$ is taken as $10 \mathrm{MPa}$.

In compression, the equations are given by CEB code as follows [26]: 


$$
\begin{aligned}
& C D I F=\frac{f_{c}}{f_{c s}}=\left(\frac{\dot{\varepsilon}}{\dot{\varepsilon}_{c s}}\right)^{1.026 \alpha} \text { for } \dot{\varepsilon} \leq 30 \mathrm{~s}^{-1} \\
& C D I F=\frac{f_{c}}{f_{c s}}=\gamma(\dot{\varepsilon})^{1 / 3} \quad \text { for } \dot{\varepsilon}>30 \mathrm{~s}^{-1}
\end{aligned}
$$

where $f_{c}$ is the dynamic compressive strength at strain rate $\dot{\varepsilon}, f_{c s}$ is the static compressive strength at $\dot{\varepsilon}_{c s}, \log \gamma=6.156 \alpha-0.49, \alpha=1 /\left(5+3 f_{c u} / 4\right)$ and $f_{c s}$ is the static cube strength (in MPa).

The $K \& C$ model [28] is adopted to determine the DIF for the reinforcements which is given as

$$
\begin{gathered}
D I F=\left(\frac{\dot{\varepsilon}}{10^{-4}}\right)^{\alpha} \\
\alpha=0.074-0.040 f_{y} / 414
\end{gathered}
$$

where $f_{y}$ is the steel yield strength in $\mathrm{MPa}$.

\section{Numerical Results}

As mentioned in Section 2.2, the last 4 slabs were demolished first followed by the rest 12 slabs simultaneously. The collapse potentials of different demolishing processes are examined in this section. For comparison purpose, the original demolishing plan, i.e. the slabs are demolished one by one, is also discussed.

In numerical simulations, since the explicit solver is used, the gravity load is applied dynamically. Applying gravity load induces the bridge structure to vibrate although it is applied slowly. This undesirable dynamic effect is removed by applying a large damping to the system [23] at the first 0.1 sec to make the system rest. After the bridge is stable, part (5) in Fig. 8 is then removed from the model.

\subsection{Demolishing processes}




\subsubsection{Demolishing slabs 13-16}

According to what had happened, demolishing of the last 4 slabs is simulated first. Fig. 9 shows the collapse process. Fig. 9(a) is the original model, part (5) of slabs 13-16 is removed at 0.1 sec as shown in Fig. 9(b). The broken slabs drop to the ground due to the gravity load and impact the ground at $1.33 \mathrm{~s}$ as shown in Fig. 9(c). The left ends of the falling slabs move off from the bearing supports and impact on pier \#109 at $1.44 \mathrm{~s}$ (Fig. 9(d)), and then slide down along the surface of the pier (Fig. 9(e)) and finally hit the ground at $2.5 \mathrm{~s}$ (Fig. 9(f)). It is obvious that the simultaneous demolishing of the last 4 slabs does not cause the progressive collapse of the bridge. However, although the impacting force from the falling slabs does not knock off the pier, it causes local damages to pier \#109. This simulation result agrees with the conditions observed during the real demolishing work. Fig. 10 shows the damage of pier \#109 by impact of the falling slabs.

It can be observed that the impacting force results in concrete crushing damage near the impacting location, pushes pier \#109 towards pier \#108, and also results in slight torsional response of the pier. Large impacting force also damages some of the reinforcement bars. It should be noted that the slabs are modelled by elastic material and the damage of slabs is not considered in the study. In real case, some damage to the slabs is also expected. Damage of the slab material will absorb certain impact energy, which is neglected in the present study. Therefore, the simulation results obtained with the elastic slab assumption might slightly overestimate the pier damage.

\subsubsection{Demolishing slabs 1-12}

The above simulation demonstrates that demolishing the last 4 slabs simultaneously did not cause bridge pier collapse but caused some local damage to the pier. In this section, the impact from 12 falling slabs on the pier is simulated as in the second stage of demolishing work described above. For simplicity, the damage induced by the impact from the falling 
slabs 13-16 as shown in Fig. 10 is not considered. This will lead to some underestimation of the pier damage. However, the primary purpose of this simulation is to demonstrate that impact from 12 falling slabs is enough to collapse the bridge pier owing to the large impacting force and the pier is not designed to resist such a lateral impact. The results will show that even if the pier has no any prior damage, it is not strong enough to resist the impact.

Fig. 11(a) shows the original model. As shown in Figs. 11(b)-(d), the process before the slabs begin to impact pier \#109 is the same as that in Section 4.1.1. Pier \#109 begins to deform toward pier \#108 after being impacted (Fig. 11(e)) by the falling slabs. Obvious shear failure occurs at about $2 \mathrm{~m}$ above the ground at Section A-A (Fig. 11(f)), where the cross sectional area changes as shown in Fig. 3. The reason of failure will be further discussed in Section 4.2. As also can be seen from the figure, the shear failure induced the collapse of pier \#109. The upper part of the pier falls to the ground due to gravity, which results in the fall of the second span owing to the loss of support. The fallen upper part of pier \#109 reaches the ground at 2.38 s (Fig. 11(g)), and it is eroded to avoid computer overflow due to large deformation and continuous contact. The second span drops to the ground at $2.92 \mathrm{~s}$ (Fig. 11(h)) and its right end begins to impact pier \#108 at $2.99 \mathrm{~s}$ (Fig. 11(i)). Pier \#108 will collapse as pier \#109 due to the impact loading, which induces progressive collapse of the bridge. However, in this study, to save the computational effort, damage of pier \#108 is not modelled. As will be demonstrated in Section 4.2, the impact between the second span and pier \#108 will lead to the collapse of pier \#108.

The lower part of pier \#109 below the shear failure section remains on the ground as shown in Fig. 12. The height of the remaining part is about $1.56 \mathrm{~m}$ in the numerical study, which is almost the same as that in Fig. 6(c), where the remaining part is about $1.63 \mathrm{~m}$. 
This result also demonstrates that the model developed in the present study gives good predictions of the bridge failure.

\subsubsection{Demolishing slabs one by one}

The original plan of the mechanical demolishing is that the slabs will be demolished one by one. The above simulations revealed that demolishing first 4 slabs simultaneously did not cause pier collapse owing to the relatively small impact force. However, these 4 slabs locate only at the edge of the pier. It will be interesting to know the situation of the bridge if the original demolishing plan, i.e., demolishing the slabs one by one, is followed. This section presents numerical simulations of the original demolishing process. To save computational effort, and also because the bridge is symmetrical along the axial direction, only demolishing half of the slabs, i.e., slabs 1-8, are simulated. Fig. 13 shows the collapse process. It can be found that the collapse of each slab generates local crushing damage to pier \#109 at the surrounding area right underneath the collapsed slab. This indicates that the collapse of a particular slab only results in localized damage to the pier. Fig. 14 shows the damage on pier \#109 after first 8 slabs dropping to the ground successively. It is obvious that pier collapse will not occur and hence progressive collapse will not be triggered. Relatively serious damage is generated when slab 5 is demolished. This is because the vertical reinforcements in the pier beneath slab 5 are sparse as shown in Figs. 2 and 3, which makes the base of the cantilever relatively easy to be damaged. This observation indicates that should the original demolishing plan have been followed, the tragic accident could have not occurred.

\subsection{Failure analysis}

As shown in Fig. 11, pier \#109 is sheared off at section A-A because the shear force exceeds the shear strength of the pier. This section presents a simple analytical approach to assess this damage. 
The nominal shear strength of the pier can be computed based on different design codes. For example, the ACI Building Code [29] and AASHTO specifications [30] take into consideration the concrete contribution $\left(V_{c}\right)$ and steel contribution $\left(V_{s}\right)$, and the nominal shear strength $V_{n}$ is given as follows:

$$
V_{n}=V_{c}+V_{s}
$$

where

$$
\begin{gathered}
V_{c}=2\left(1+\frac{P}{2000 A_{g}}\right) \sqrt{f_{c}^{\prime}} b_{w} d \text { (lbs) } \\
V_{s}=\frac{A_{v} f_{y h} d}{s}
\end{gathered}
$$

In the above equations, $P$ is the axial load (in lbs), $A_{g}$ is the gross cross-section area (in in $^{2}$ ), $f_{c}^{\prime}$ is the concrete compressive strength (in psi), $b_{w}$ is the width of the cross section (in in), and $d$ is the distance from the extreme compression fibre to centroid of the tension reinforcement (in in), and $b_{w} d$ can be taken as $0.8 A_{g} . A_{v}$ is the area of transverse steel, $f_{y h}$ is the yield strength of the transverse steel, and $s$ is the vertical distance between hoops.

With the parameters given in the previous sections, for section A-A shown in Fig. 3, it has $V_{c}=4407.9 \mathrm{kN}$ and $V_{s}=212.65 \mathrm{kN}$ and the nominal shear strength is $4620.55 \mathrm{kN}$. It should be noted that, the above results are obtained by considering half weight of the second span and neglecting that from the falling span in calculating the axial load. In fact, when the slabs of the first span drop from the pier, they generate a vertical impacting force on the pier initially, and followed by a vertical force through friction of the falling span with the pier. Neglecting this axial force leads to a slight underestimation of the actual nominal shear strength of the bridge pier. Moreover, Eqs. (8) and (9) are obtained based on the quasi-static analyses, the nominal shear strength of the pier can be slightly higher under dynamic impact loading. However, because of the poor understanding of the dynamic 
increment on concrete and steel shear strengths, in practice, strain rate effect on RC structure shear strength is usually neglected.

Figs. 15-17 show the numerically simulated horizontal impacting forces on the pier from different numbers of falling slabs. As shown in Figs. 15 and 16, the duration of the impacting force is quite short and it can be approximately regarded as a triangular pulse. It is well known that for a system subjected to a pulse force, the structural response can be amplified or de-amplified and the maximum response is related to the ratio of $t_{d} / T_{n}$ [31], where $t_{d}$ is the pulse duration and $T_{n}$ is the natural vibration period of the system. For the pier shown in Fig. 2, it is found that the first natural vibration period is $T_{n}=0.176 \mathrm{~s}$ based on an eigenvalue analysis.

It can be seen from Fig. 15 that the maximum pounding force due to demolishing slabs $13-16$ is $4.24 \mathrm{MN}$, and the duration $t_{d}$ is $0.03 \mathrm{~s}$. For a triangular pulse, the dynamic deamplification factor is about 0.54 when $t_{d} / T_{n}=0.03 / 0.176=0.17$ [31]. The de-amplified impacting force on pier \#109 is thus $4.24 \times 0.54=2.29 \mathrm{MN}$, which is smaller than the shear strength of pier \#109. Therefore, it generates crushing damages on concrete and damages some reinforcement bars, but the pier does not collapse as shown in Fig. 10. When the first 12 slabs are demolished simultaneously, the maximum impacting force on pier \#109 reaches $15.70 \mathrm{MN}$ and the duration is $0.05 \mathrm{~s}$ (Fig. 16(a)). The dynamic de-amplification factor is about 0.89 when $t_{d} / T_{n}=0.05 / 0.176=0.274$ and the de-amplified peak loading is 13.97 MN, which is substantially higher than the nominal shear strength of the pier. Therefore the pier collapses owing to insufficient shear strength to resist such a large impacting force. The horizontal impacting force on pier \#108 from the impact of the falling span is $10.12 \mathrm{MN}$ and the duration is also $0.05 \mathrm{~s}$ (Fig. 16(b)). The de-amplified impacting force is $9.00 \mathrm{MN}$, which is also larger than the shear strength of the pier. Therefore pier \#108 also collapses owing to insufficient shear strength like pier \#109. 
Similar damage is expected to adjacent bridge spans and piers, leading to progressive collapse of the bridge structure. It is interesting to note that the impacting force on pier \#108 is smaller than that on pier \#109 although the weight of the falling superstructure is larger (16 slabs fall in the second span) than that of the first span (only 12 slabs). This is because of the partial support provided by the damaged pier \#109 as well as the relatively longer span length which results in a slightly smaller impact angle. When the slabs are demolished one by one, the resulted impact forces vary from 0.69 to $1.67 \mathrm{MN}$ as shown in Fig. 17. The durations are between 0.03 and $0.06 \mathrm{~s}$, resulting in the dynamic amplification factors vary from 0.54 to 1.07 . The amplified impacting forces are smaller than the shear strength of pier \#109. Therefore, if the demolishing work had followed the initial plan, the accident could have not happened and the falling slabs would only have caused some local damages on bridge piers as shown in Fig. 14.

\section{Progressive Collapse Vulnerability}

The above analyses indicate that multi-span simply-supported bridge might experience the domino-type progressive collapse when failure of one pier occurs. This makes such bridge type extremely vulnerable because collapse of one pier could be induced by many incidents such as terrorist bombing or vehicle impact, etc. Because the multi-span simplysupported bridges are common designs in viaduct in many metropolitan areas, failure of such a bridge could be catastrophic. Therefore, it is important to prevent such a catastrophic progressive collapse event from occurring.

The reason for this type of collapse is because no alternative load path can be formed when one pier is damaged since the piers are the only supporting members that the forces from the deck can be transferred to the ground. To resist progressive collapse, structures should be designed to have sufficient strength and redundancy. The requirement for 
structural resistance to progressive collapse is not yet consistently embodied in the design codes. Even when progressive collapse is mentioned in some documents, most of them are for buildings. A review of these standards can be found in [8]. The specifications for bridge progressive collapse resistance are relatively less. Starossek [32] provides some suggestions on how to prevent bridges from progressive collapse. 5 different methods are proposed, i.e., event control, protection, increased local resistance, alternative load paths and isolation by segmentation, in which event control and protection are non-structural method and the other methods are for the structure itself.

As discussed above, Hongqi Viaduct will not collapse progressively if the slabs are demolished one by one. The vulnerability of progressive collapse can be reduced if the piers are designed with larger dimensions. This will increase the resistance of piers to shear failure. Moreover, the progressive collapse can be prevented or limited by setting segment borders to the bridge. For example, instead of designing wall-type piers for the whole bridge, some other types of piers can be designed every a few spans. The initial collapse can be prevented from progressing at these piers and will form a border to the bridge. Another possible way is to use T-shaped piers to support the deck so that the failure of one pier or falling of one span will not impact on the adjacent piers. Nevertheless, detailed discussions on how to prevent possible progressive collapse of bridge structures is beyond the scope of present study. The progressive collapse incident of Hongqi Viaduct and the results presented in this paper demonstrate the extreme vulnerability of multi-span simplysupported bridges to progressive collapse. As such designs can be found in many viaducts in metropolitan areas, attentions are probably needed to be paid on the safety of such bridges. 


\section{Conclusions}

Hongqi Viaduct collapsed progressively during the mechanical demolishing of the bridge on May 17, 2009. The accident resulted in the loss of 9 lives and 16 injuries. This paper carries out numerical simulation on the bridge progressive collapse process. A simple analytical approach is presented to analyse the failure. The progressive collapse vulnerability of multi-span simply-supported bridge is discussed. Following conclusions are obtained:

- A detailed 3D finite element is developed to simulate the progressive collapse of the multi-span simply-supported bridge. The developed model captures the collapse process of the bridge.

- The multi-span simply-supported bridge with wall-type piers might be vulnerable to domino-type progressive collapse due to the limited shear strength of the supporting piers.

- Hongqi Viaduct will not collapse progressively if the slabs are demolished one by one.

- Current design code specifications to prevent bridges from progressive collapse are limited. Systematic study on bridge progressive collapse mitigation method is needed.

\section{Acknowledgements}

Financial supports from the National Natural Science Foundation of China (Grant Nos. 51278163 and 51478159) are acknowledged. Partial financial support from Australian Research Council (ARC) under Linkage Project LP110200906 is also greatly acknowledged. 


\section{References}

[1] ASCE/SEI 7-05. Minimum design loads for buildings and other structures. NY: American Society of Civil Engineers; 2005.

[2] Salem SH, El-Fouly AK, Tagel-Din HS. Toward an economic design of reinforced concrete structures against progressive collapse. Eng Struct 2011; 33(12): 3341-50.

[3] Starossek U. Progressive collapse of structures. London: Thomas Telford; 2009.

[4] Lichtenstein AG. The silver bridge collapse recounted. J Perform Constr Fac 1993; 7(4): 249-61.

[5] Xu Z, Lu X, Guan H, Ren A. Progressive-collapse simulation and critical region identification of a stone arch bridge. J Perform Constr Fac 2013; 27(1): 43-52.

[6] Astaneh-Asl A. Progressive collapse of steel truss bridges, the case of I-35W collapse. In: Proceedings of $7^{\text {th }}$ international conference on steel bridges, Guimaraes, Portugal; 2008. p.1-10.

[7] Starossek U. Typology of progressive collapse. Eng Struct 2006; 29(9): 2302-07.

[8] Mohamed OA. Progressive collapse of structures: annotated bibliography and comparison of codes and standards. J Perform Constr Fac 2006; 20(4): 418-28.

[9] Salem HM, El-Fouly AK, Tagel-Din HS. Toward an economic design of reinforced concrete structures against progressive collapse. Eng Struct 2011; 33 (12): 3341-50.

[10]Hao H, Wu C, Li Z, Abdullah AK. Numerical analysis of structural progressive collapse to blast loads. Trans Tianjin Univ 2006; 12(Suppl.): 31-4.

[11]Li J, Hao H. Numerical study of structural progressive collapse using substructural technique. Eng Struct. 2013; 52:101-13. 
[12] Lu X, Lu X, Guan H, Ye L. Collapse simulation of reinforced concrete high-rise building induced by extreme earthquakes. Earthquake Eng Struct Dyn 2013; 42(5): 705-23.

[13]Lynn KM, Isobe D. Structural collapse analysis of framed structures under impact loading using ASI-Gauss finite element method. Int J Impact Eng 2007; 34 (9): 150016.

[14]Lynn KM, Isobe D. Finite element code for impact collapse problems of framed structures. Int J Numer Methods Eng 2007; 69(12): 2538-63.

[15]Khandelwal K. Multi-scale computational simulation of progressive collapse of steel frames 2008; PhD thesis, University of Michigan, Ann Arbor, MI.

[16]Ghali A, Tadros G. Bridge progressive collapse vulnerability. J Struct Eng 1997; 123(2): 227-31.

[17] Starossek U. Progressive collapse study of a multi-span bridge. Struct Eng Int 1999; 9(2): 121-25.

[18]Wolff M, Starossek U. Cable loss and progressive collapse in cable-stayed bridges. Bridge Struct 2009; 5(1): 17-28.

[19]Wolff M, Starossek U. Robustness assessment of a cable-stayed bridge. In: International conference on bridge maintenance, safety and management, Seoul, Korea; 2008. p.1-7.

[20]Hao H, Tang EKC. Numerical simulation of a cable-stayed bridge response to blast loads, part II: damage prediction and FRP strength. Eng Struct 2010; 32(10): 3193-205.

[21]Aoki Y, Valipour H, Samali B, Saleh A. A study on potential progressive collapse responses of cable-stayed Bridges. Adv Struct Eng 2013; 16(4): 689-706.

[22]ANSYS. ANSYS user manual. ANSYS, Inc; 2002. 
[23]LS-DYNA. LS-DYNA user manual. Livermore Software Technology Corporation; 2007.

[24] Sha Y, Hao H. Laboratory tests and numerical simulations of barge impact on circular reinforced concrete piers. Eng Struct 2013; 46: 593-605.

[25]Bi K, Hao H. Numerical simulation of pounding damage to bridge structures under spatially varying ground motions. Eng Struct 2013; 46: 62-76.

[26]Comite Euro-International du Beton. Concrete structures under impact and impulsive loading. CEB Bulletin 187. Switzerland: Federal Institute of Technology Lausanne; 1990.

[27] Malvar LJ, Ross CA. Review of strain rate effects for concrete in tension. Amer Concr Inst Mater J 1998; 95(6): 735-39.

[28]Malvar LJ. Review of static and dynamic properties of steel reinforcing bars. Concr Inst Mater J 1998; 95(6): 609-16.

[29]ACI. Building code requirements for structural concrete (ACI 318-05) and commentary (ACI 318R-05). Farmington Hills, MI: American Concrete Institute, 2005.

[30]AASHTO. Standard specifications for highway bridges. $16^{\text {th }}$ ed. Washington DC: American Association of State Highway and Transportation Officials, 1997.

[31]Chopra AK. Dynamics of structures: theory and applications to earthquake engineering. New Jersey: Prentice-Hall; 1995.

[32] Starossek U. Disproportionate collapse: terminology and procedures. J Perform Constr Fac 2010; 24(6): 519-27. 
Table 1. Average yield strength and ultimate strength of reinforcement bars

\begin{tabular}{cccc}
\hline Size & $\phi 18$ & $\phi 12$ & $\phi 10$ \\
Average yield strength (MPa) & 347 & 498 & 470 \\
Average ultimate strength (MPa) & 526 & 571 & 574 \\
\hline
\end{tabular}

Table 2. Material properties.

\begin{tabular}{|c|c|c|c|c|}
\hline Material & Location & LS-DYNA model & Parameter & Value \\
\hline \multirow{8}{*}{ Concrete } & \multirow[b]{2}{*}{ Pier \#109 } & \multirow{2}{*}{$\begin{array}{c}\text { *MAT_CONCRETE_DAMAGE_REL3 } \\
\text { (MAT_72REL3) }\end{array}$} & Mass density & $2400 \mathrm{~kg} / \mathrm{m}^{3}$ \\
\hline & & & $\begin{array}{l}\text { Compressive } \\
\text { strength }\end{array}$ & $38.7 \mathrm{MPa}$ \\
\hline & \multirow{3}{*}{$\begin{array}{l}\text { Pier \#110 } \\
\text { Pier \#108 }\end{array}$} & \multirow{3}{*}{ *MAT_ELASTIC } & Mass density & $2500 \mathrm{~kg} / \mathrm{m}^{3}$ \\
\hline & & & $\begin{array}{l}\text { Young's } \\
\text { modulus }\end{array}$ & $32.5 \mathrm{GPa}$ \\
\hline & & & Poisson's ratio & 0.2 \\
\hline & \multirow{3}{*}{ Slab } & \multirow{3}{*}{ *MAT_ELASTIC } & Mass density & $2241 \mathrm{~kg} / \mathrm{m}^{3}$ \\
\hline & & & $\begin{array}{l}\text { Young's } \\
\text { modulus }\end{array}$ & $34.5 \mathrm{GPa}$ \\
\hline & & & Poisson's ratio & 0.2 \\
\hline \multirow{7}{*}{ Steel } & \multirow{7}{*}{ Pier \#109 } & \multirow{7}{*}{$\begin{array}{c}\text { *MAT_PIECEWISE_LINEAR_PLASTICITY } \\
\text { (MAT_24) }\end{array}$} & Density & $7800 \mathrm{~kg} / \mathrm{m}^{3}$ \\
\hline & & & $\begin{array}{l}\text { Young's } \\
\text { modulus }\end{array}$ & 200GPa \\
\hline & & & Poisson's ratio & 0.3 \\
\hline & & & Yield stress & 347/498/470 MPa * \\
\hline & & & Ultimate stress & 526/571/574 MPa * \\
\hline & & & $\begin{array}{l}\text { Tangent } \\
\text { modulus }\end{array}$ & $800 \mathrm{MPa}$ \\
\hline & & & Failure strain & 0.12 \\
\hline
\end{tabular}

*: for $\phi 18, \phi 12$ and $\phi 10$ reinforcements respectively. 


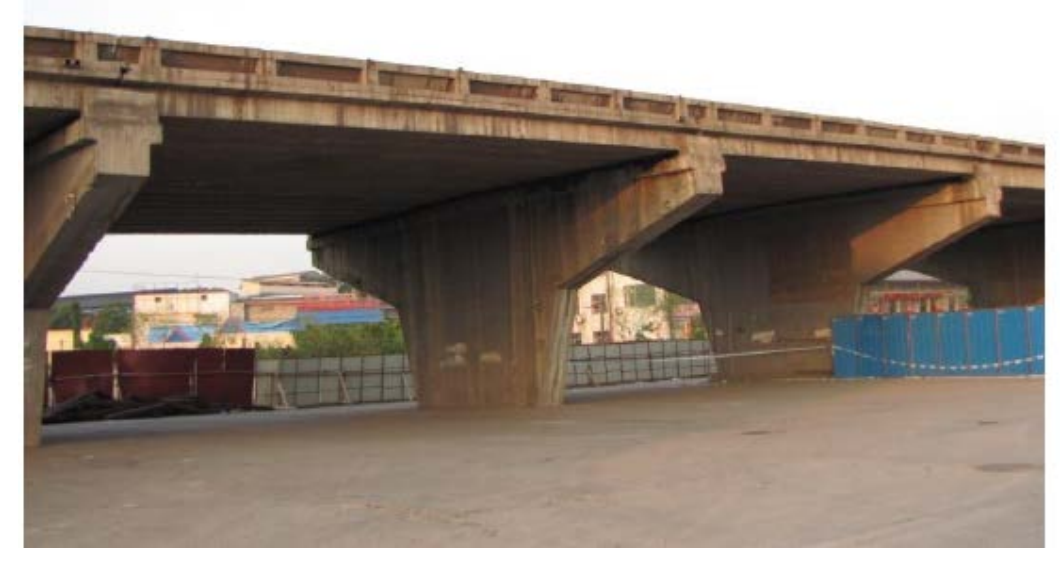

Fig.1. Typical view of Hongqi Viaduct (before collapse)
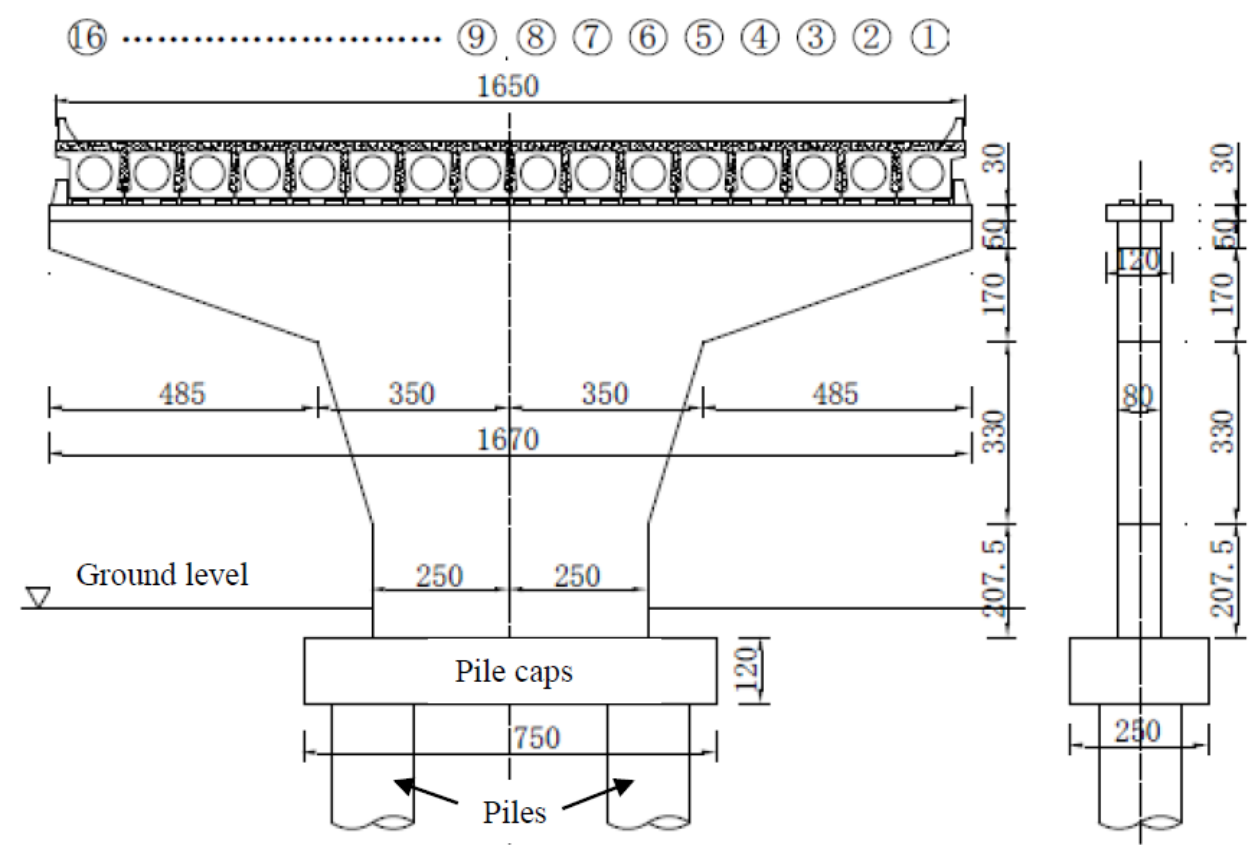

Fig. 2. Numbering of the slabs and cross sections of the pier (unit: $\mathrm{cm}$ ) 


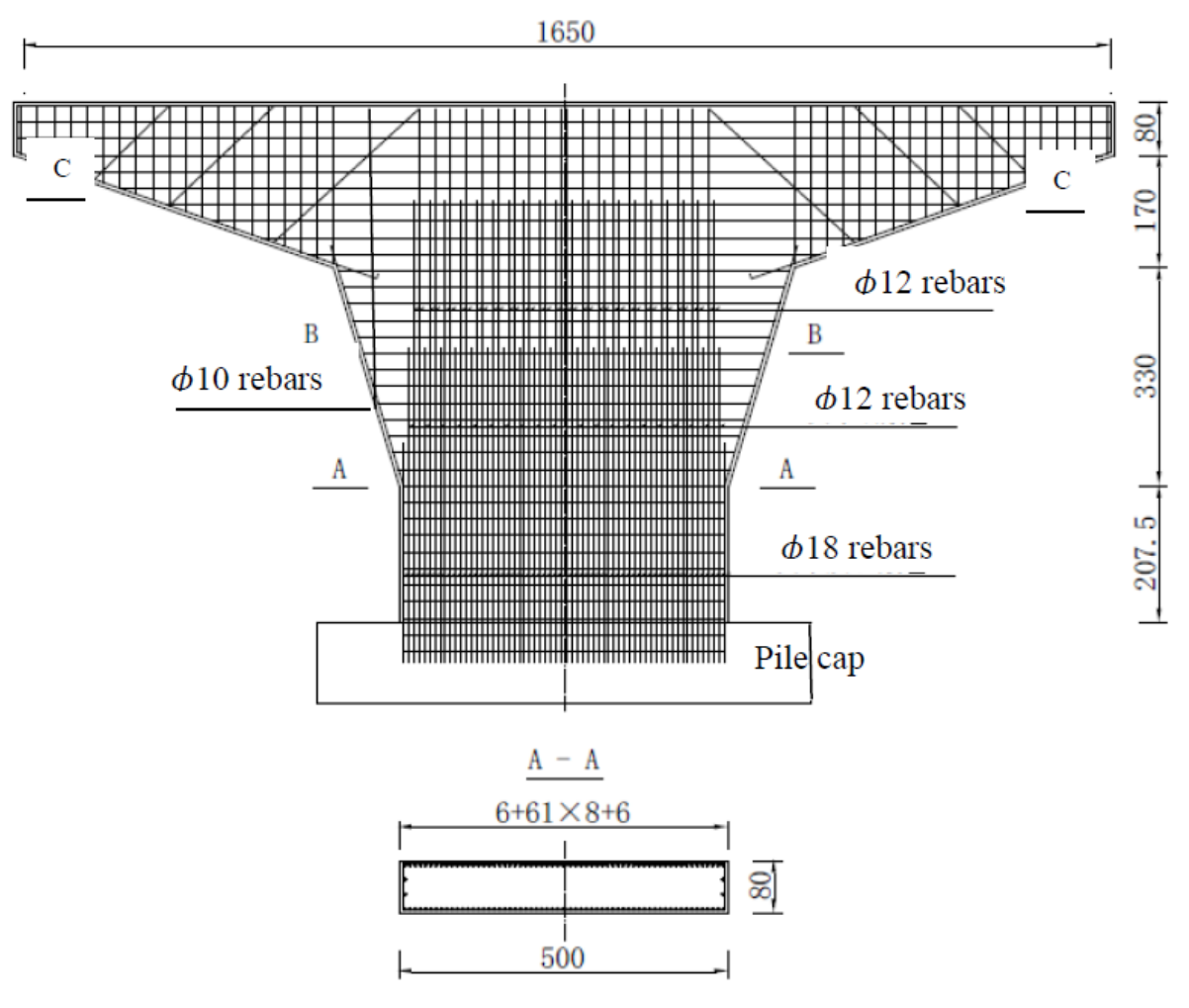

Fig. 3. Reinforcement bars in the pier (unit: $\mathrm{cm}$ )

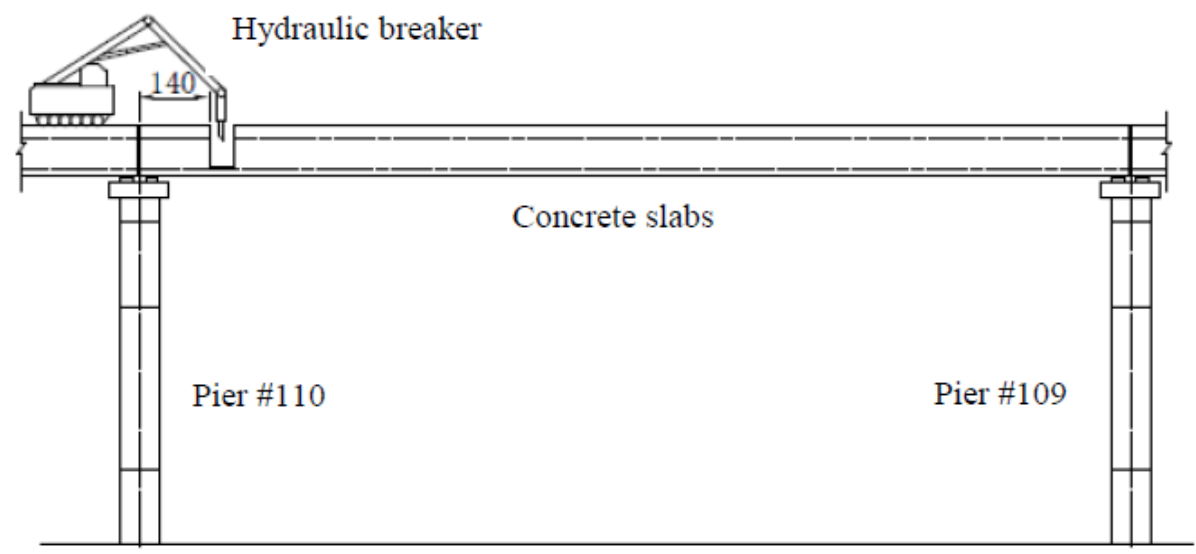

Fig. 4. Mechanical demolishing method 


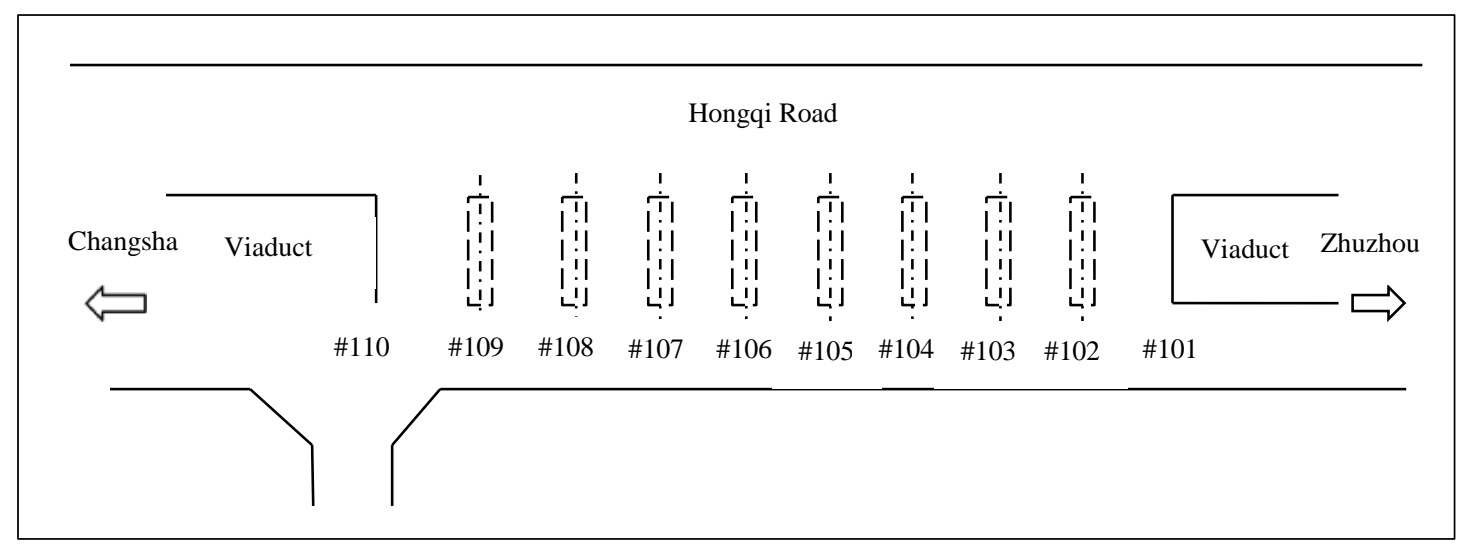

Fig. 5. Plan view of the collapsed spans
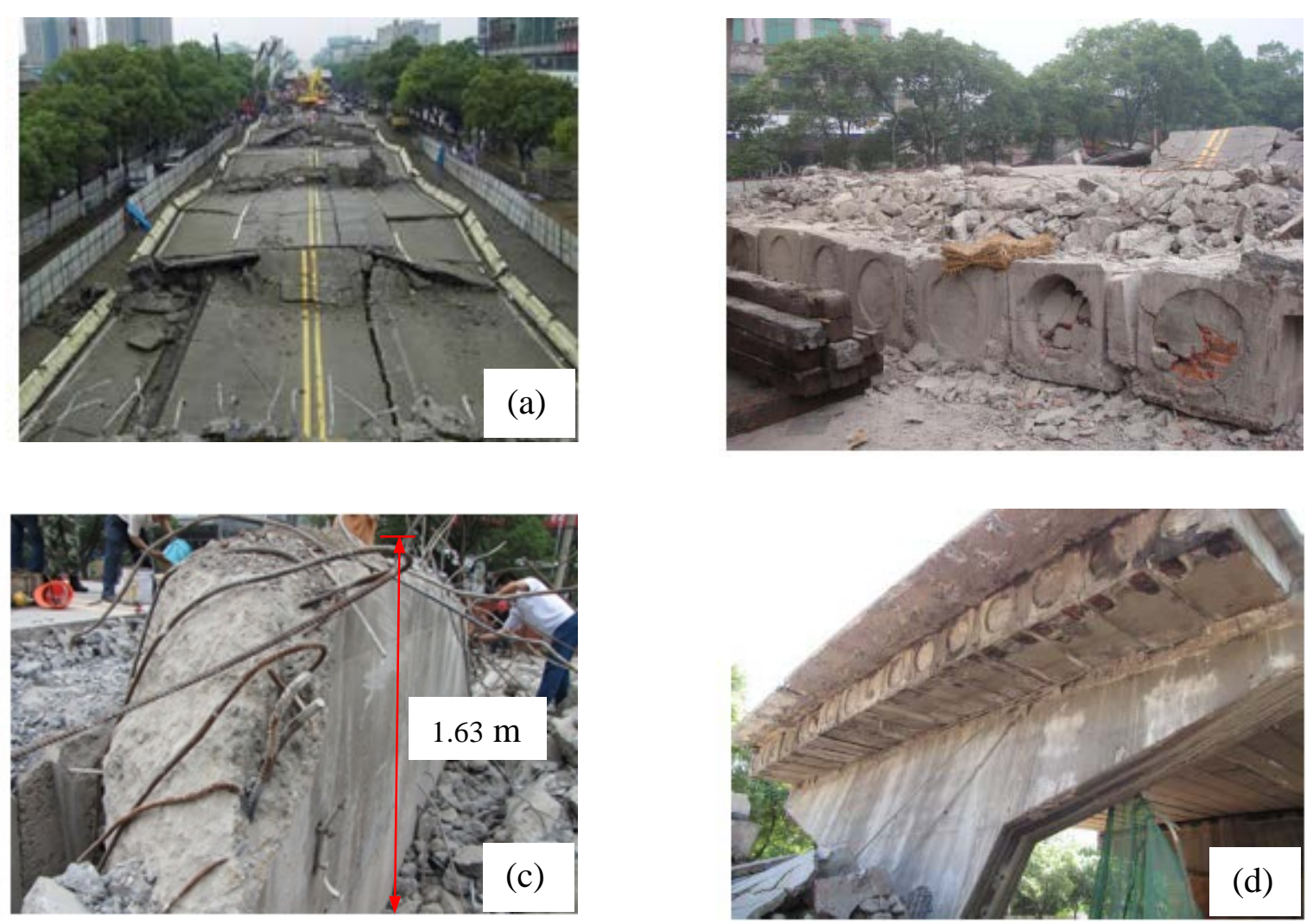

Fig. 6. Hongqi Viaduct after collapse: (a) overview, (b) collapsed slabs, (c) remaining pier (\#109) and (d) pier \#101 

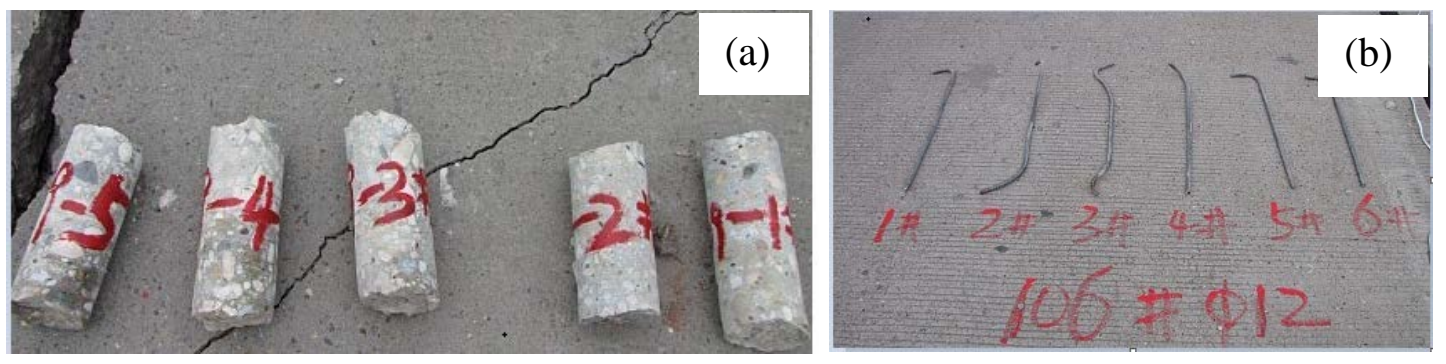

Fig. 7. Samples: (a) concrete and (b) reinforcement ( $\phi 12)$

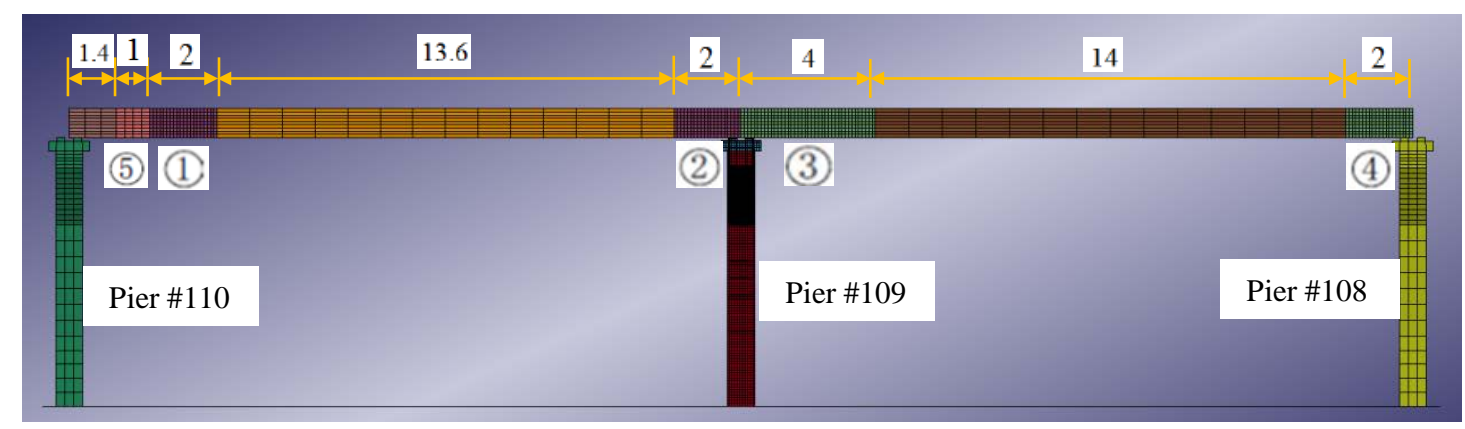

Fig. 8. Elevation view of the finite element model (unit: m) 



Fig. 9. Collapse process of simultaneously demolishing slabs 13-16: (a) $t=0.0 \mathrm{~s}$, (b) $t=0.1 \mathrm{~s}$, (c) $t=1.33 \mathrm{~s}$, (d) $\mathrm{t}=1.44 \mathrm{~s},(\mathrm{e}) \mathrm{t}=1.50 \mathrm{~s}$ and (f) $\mathrm{t}=2.5 \mathrm{~s}$


Fig. 10. Detailed observation of damage on pier \#109 due to demolsihing slabs 13-16: (a) elevation view and (b) general view 

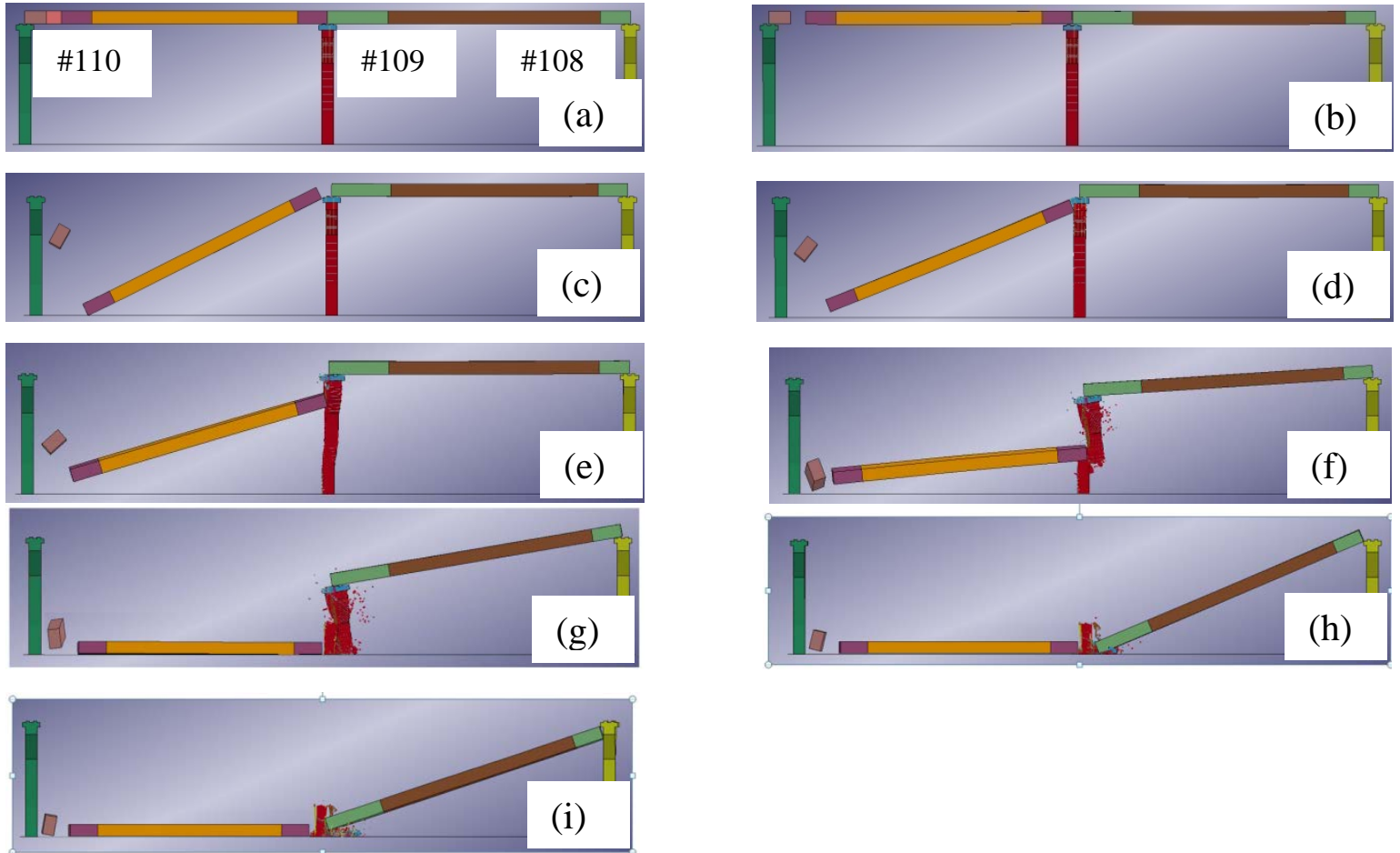

Fig. 11. Collapse process of simultaneously demolishing slabs 1-12: (a) $t=0.0 \mathrm{~s}$, (b) $t=0.1 \mathrm{~s}$, (c) $t=1.33 \mathrm{~s}$, (d) $t=1.44 \mathrm{~s}$, (e) $\mathrm{t}=1.60 \mathrm{~s}$, (f) $\mathrm{t}=2.00 \mathrm{~s}$, (g) $\mathrm{t}=2.38 \mathrm{~s}$, (h) $\mathrm{t}=2.92 \mathrm{~s}$ and (i) $\mathrm{t}=2.99 \mathrm{~s}$



Fig. 12. The remaing part of pier \#109 





Fig. 13. Collapse process of demolishing slabs one by one: (a) demolishing slab 1 at $t=0.1$ $\mathrm{s}$, (b) demolishing slab 2 at $\mathrm{t}=2.6 \mathrm{~s}$, (c) demolishing slab 3 at $\mathrm{t}=5.1 \mathrm{~s}$, (d) demolishing slab 4 at $\mathrm{t}=7.6 \mathrm{~s}$, (e) demolishing slab 5 at t $=10.1 \mathrm{~s}$, (f) demolishing slab 6 at t=12.6 s, (g) demolishing slab 7 at $\mathrm{t}=15.1 \mathrm{~s}$, (h) demolishing slab 8 at $\mathrm{t}=17.6 \mathrm{~s}$ and (i) slab 8 dropped to the ground at $\mathrm{t}=20.1 \mathrm{~s}$

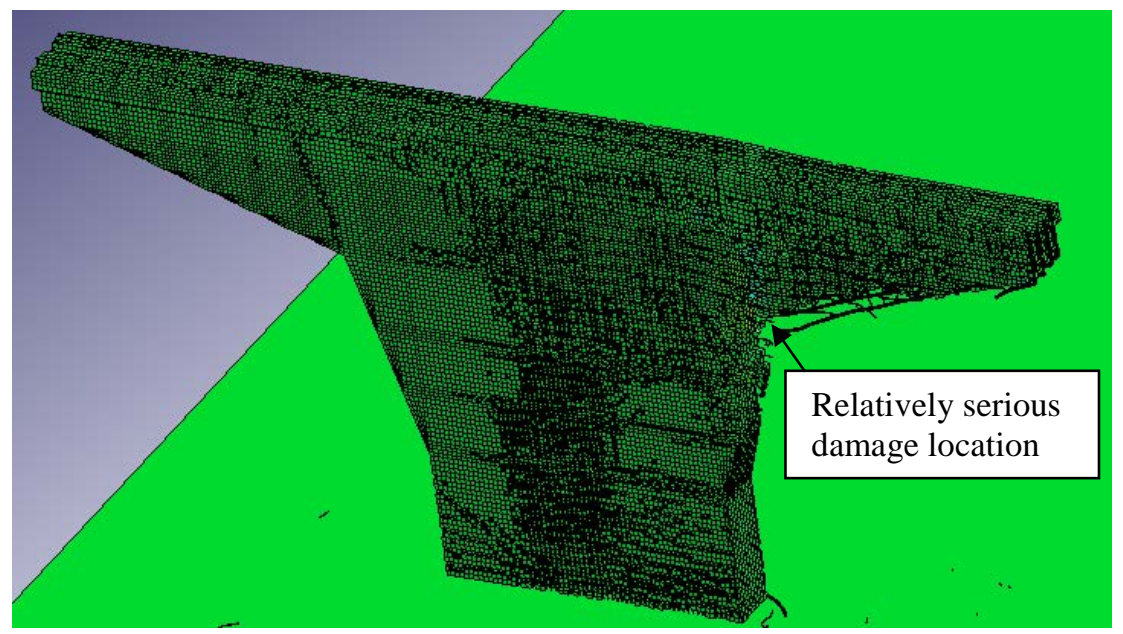

Fig. 14. Damage on Pier \#109 after the first 8 slabs being demolished one by one 


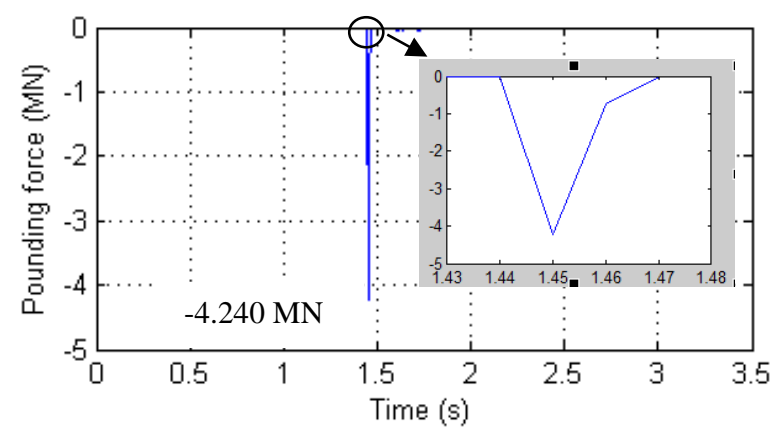

Fig. 15. Horizontal impacting force on pier \#109 due to demolishing slabs 13-16
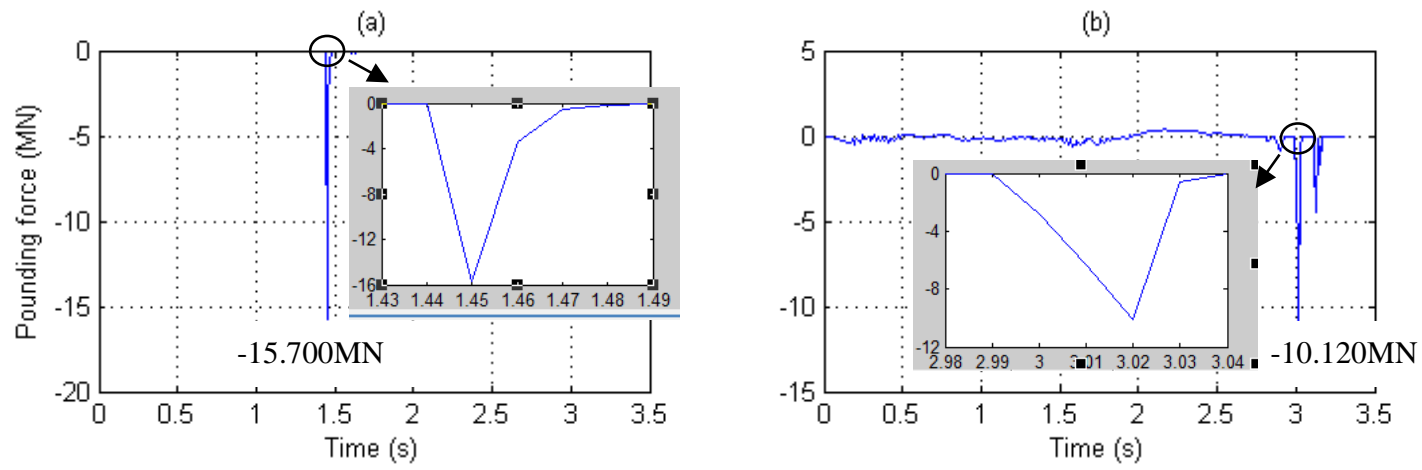

Fig. 16. Horizontal impacting forces on piers due to demolishing slabs 1-12: (a) on pier \#109 from falling slabs 1-12, and (b) on pier \#108 from falling $2^{\text {nd }}$ span 


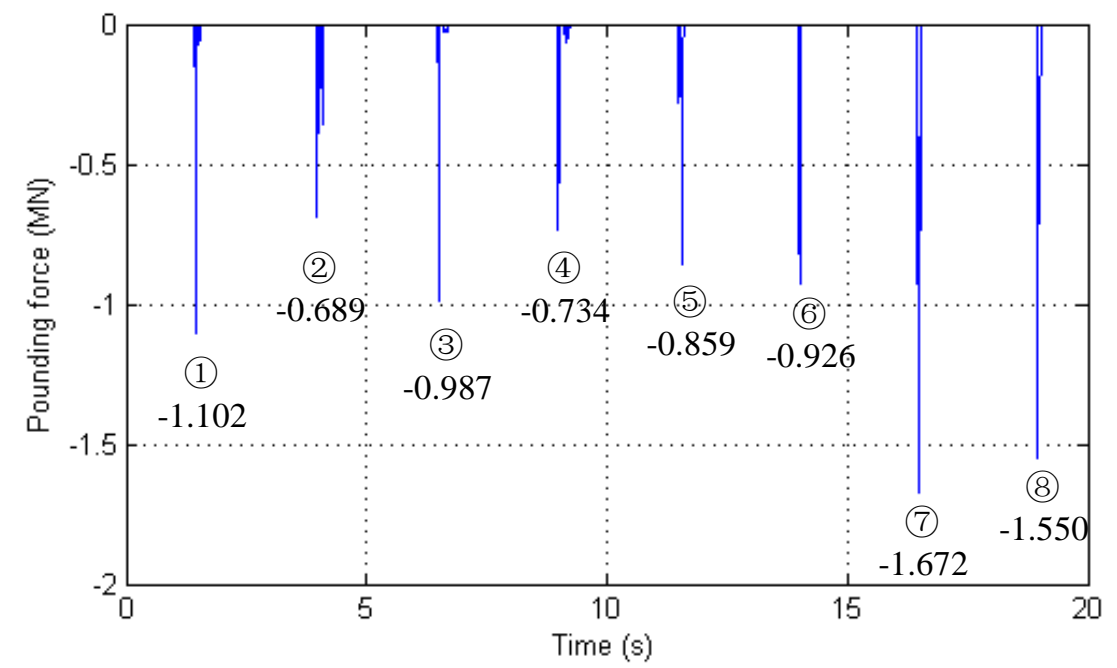

Fig. 17. Horizontal impacting forces on pier \#109 when slabs are demolished one by one 